\title{
Grayish Metal to White Ceramic; Iso Standards Are the Only Passports for Ceramic Dental Implants
}

\author{
Aous Dannan* \\ Consultant in Periodontology, Independent Researcher, Syrian Arab Republic
}

Received: November 14, 2017; Published: November 28, 2017

*Corresponding author: Dr. med. dent. Aous Dannan, Consultant in Periodontology, certified by the German Society of Periodontology (DGP), Independent Researcher, Damascus, Syrian Arab Republic; Email: aousdannan@yahoo.com

\section{Introduction}

The long-term success of titanium osseointegrated implants in periodontally healthy patients has been documented in various studies [1]. However, additional data are still needed to confirm the long-term predictability of dental implants in general. Titanium and titanium alloys are commonly used as dental implant materials. The process of integration of titanium with bone has been firstly termed by Brånemark [2] as "osseointegration". Currently, most of the commercially available implant systems are made of pure titanium or titanium alloy. However, even though titanium alloys were exceptionally corrosion-resistant because of the stability of the $\mathrm{TiO}_{2}$ oxide layer, they are not passive to corrosive attack [3]. Moreover, one of the most famous problems regarding titanium is hypersensitivity [4,5]. Due to the possible negative effects of titanium, the clinical application of implants made from different novel ceramic biomaterials has become more active. Such ceramic materials include single- and poly-crystal alumina [6], bioactive glasses [7], hydroxyapatite [8], and zirconia [9]. To date, there are several commercially available zirconia implant systems on the market [10]. Some provide both one- and two-piece designs and the others provide only one-piece designs. In order to bring dental implants into markets, they should firstly pass several mechanical tests like fatigue and dynamical loading tests.

These tests are mainly related to the ability of implant to withstand loading strength as a simulation to what is comparable to the oral cavity. Loading tests for dental implants can be denoted according to predefined standards or norms (i.e. ISO, DIN, or EN). For instance, DIN 50100 describes a load-controlled fatigue testing design at constant load amplitudes on metallic specimens and components. The endurance limit can be displayed, for example, in a fatigue strength diagrams [11]. However, this standard is not usually applicable for testing dental implants. ISO 13356:2015 specifies the requirements and corresponding test methods for a biocompatible and bio-stable ceramic bone-substitute material based on yttriastabilized tetragonal for use as a material for surgical implants. This norm imposes that a maximum of $25 \mathrm{wt} \%$ of monoclinic phase is present in test specimens after an accelerated aging test $\left(134^{\circ} \mathrm{C}\right.$ in a humid atmosphere with an air pressure of $0.2 \mathrm{MPa}$ ) [12]. ISO DIN 14801:2016 [previously known as ISO 14801:2007] specifies a method of dynamic testing of single post endosseous dental implants of the trans mucosal type in combination with their premanufactured prosthetic components [13,14], and is used in 162 member countries around the world. It is most useful for comparing endosseous dental implants of different designs or sizes [15].

This international standard is not a test of the fundamental fatigue properties of the materials from which the endosseous implants and prosthetic components are made, and, moreover, is not applicable to dental implants with endosseous lengths shorter than $8 \mathrm{~mm}$ nor to magnetic attachments. While ISO 14801:2016 simulates the functional loading of an endosseous dental implant under "worst case" conditions, it is not applicable for predicting the in vivo performance of an endosseous dental implant or dental prosthesis, particularly if multiple endosseous dental implants are used for a dental prosthesis. In our opinion, although ISO standards are equipped to encounter all possible loading situations that could take place in the mouth, they still lack more real conditions that should be taken into consideration. To simulate intraoral aging to the extent possible and, in particular, address the degradation susceptibility of metastable zirconia ceramics, an experimental setup by Spies et al. [15] tried to add some modifications that differed from ISO 14801. The mentioned norm does not include horizontal loading components or degradation accelerating environmental factors. By placing the samples of the mentioned study in a warm fluid of $60^{\circ} \mathrm{C}$ during the dynamic loading procedure, the applied testing protocol was designed to account for the specific nature of zirconia ceramics and its behavior in aqueous environments.

Furthermore, ISO 14801 dictates the simulation of a $3 \mathrm{~mm}$ bone recession. In another important trial to enhance the testing conditions of ISO 14801, Castolo et al. [16] tried to use finite element analysis to assess the influence of design parameters on the mechanical performance of an implant in regard to testing 
conditions of ISO 14801 standard. In their study, an endosseous dental implant was loaded under ISO standard 14801 testing conditions by numerical simulation, with 4 parameters evaluated under the following conditions: conditions of the contact surface area between the implant and the loading tool, length of the fixation screw, implant embedding depth, and material used for implant stiffness. Finite element analysis was used to compare the force that needed to reach the implant's yield and fracture strength. It was shown that finite element analysis made it possible to evaluate 4 performance parameters of a dental implant under ISO standard 14801 conditions. Under these conditions, the contact surface area was found to be the major parameter influencing implant performance.

\section{Conclusion}

Zirconium implants have an obvious esthetic advantage over titanium implants being "pure white", making them indistinguishable from natural teeth. Fracture, corrosion, fatigue, the possible abrasion actions that take place within the connected parts of implant, and other relevant terms are all important mechanical factors that should be taken into consideration before introducing ceramic dental implants in the market. Such mechanical features should be tested through previously defined standards or norms. To date, two separate international ISO standards are available for testing dental implants; namely ISO 13356 and ISO 14801. However, there is still a recent debate regarding these currently applicable ISO standards due to the fact that they are not addressing the in vivo aging behavior of zirconia dental implants to verify their real pre-clinical safety.

\section{References}

1. Nicoli LG, Oliveira GJPLd, Lopes BMV, Marcantonio C, Zandim-Barcelos DL, et al. (2017) Survival/Success of Dental Implants with Acid-Etched Surfaces: A Retrospective Evaluation After 8 to 10 Years. Brazilian Dental Journal 28(3): 330-336.

2. Branemark P, Hansson BO, Adell R, Breine U, LindstromJ, et al. (1977) Osseointegrated implants in the treatment of the edentulous jaw. Experience from a 10-years period. Scand J Plast Reconstr Surg 16: 1-132.
3. Chaturvedi T (2009) An overview of the corrosion aspect of dental implants (titanium and its alloys). Indian Journal of Dental Research 20(1): 91-98.

4. Sicilia A, Cuesta S, Coma G, Arregui I, Guisasola C, et al. (2008) Titanium allergy in dental implant patients: a clinical study on 1500 consecutive patients. Clinical oral implants research 19(8): 823-835.

5. Wenz HJ, Bartsch J, Wolfart S, Kern M (2008) Osseointegration and clinical success of zirconia dental implants: a systematic review. International Journal of Prosthodontics 21(1): 27-36.

6. Kawahara H, Hirabayashi M, Shikita T (1980) Single crystal alumina for dental implants and bone screws. Journal of Biomedical Materials Research 14(5): 597-605.

7. Schepers E, De Clercq M, Ducheyne P (1987) Fiber-reinforced bioactive glass: a possible dental implant material. Biomedizinische Technik Biomedical engineering 32(12): 309-312.

8. Simunek A, Kopecka D, Cierny M, Krulichova I (2005) A six-year study of hydroxyapatite-coated root-form dental implants. West indian medical journal 54(6): 393-397.

9. Volz U, Blaschke C (2004) Metal-free reconstruction with zirconia implants and zirconia crowns. Quintessence J Dent Technol 2: 324-230.

10. Patil R (2015) Zirconia versus titanium dental implants: A systematic review. Journal of Dental Implants 5(1): 39-42.

11. Rösler J, Harders H, Baeker M (2007) Mechanical behavior of engineering materials: metals, ceramics, polymers, and composites: Springer Science \& Business Media.

12. ISO 13356 (2017) Implants for surgery-ceramic materials basedon yttria-stabilized tetragonal zirconia (Y-TZP): ISO 13356:2008(E) $\left(2^{\text {nd }}\right.$ edn.). p.1-20.

13. Rosentritt M, Behr M, Preis V (2016) A Critical Evaluation of Fatigue Studies for Restorative Materials in Dentistry. Current Oral Health Reports 3(3): 221-228.

14. Schimmel M, Rausch P (2015) Fatigue-Prüfsystem für Implantat systeme nach DIN EN ISO 14801. Implantologie Journal (3): 38-41.

15. Spies BC, Nold J, Vach K, Kohal R-J (2016) Two-piece zirconia oral implants withstand masticatory loads: an investigation in the artificial mouth. J Mech Biomed Mater 53: 1-10.

16. de la Rosa Castolo G, Perez SVG, Arnoux P-J, Badih L, Bonnet F, et al. (2017) Mechanical strength and fracture point of a dental implant under certification conditions: A numerical approach by finite element analysis. J Prosth Dent S0022-3913(17): 30360-30368.

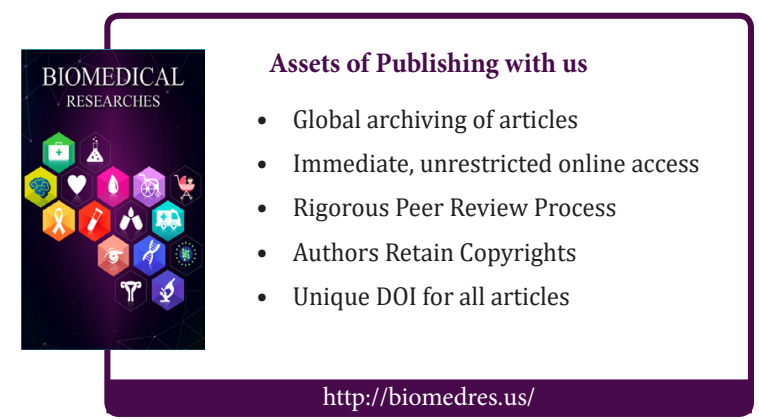

